\title{
Dorsolateral Sacral Plexus: An Anatomical Description
}

\author{
Joseph D Fortin ${ }^{1 *}$ and Ryan S Dill ${ }^{2}$ \\ ${ }^{1}$ Medical Director: Spine Technology and Rehabilitation, Clinical Professor: Indiana University School of Medicine, USA \\ ${ }^{2}$ Department of PM\&R, University of Alabama at Birmingham, Birmingham, AL USA
}

*Corresponding author: Joseph D Fortin, Spine Technology and Rehabilitation, 9502 Lima Road, Suite 103 Fort Wayne, USA.

Received Date: February 16, 2021

Published Date: March 17, 2021

\section{Abstract}

Previous studies demonstrate the rich innervation of the sacroiliac joint by the sacral dorsal rami lateral branches, as well as its link to low back pain and sciatica. However, no study has detailed the terminations of the lateral branches, nor their branching structures lateral to the joint proper In this study, we investigated the path and connectivity of the dorsal sacral rami and their relationship to the sacroiliac joint and surrounding tissues. 10 cadaveric hemipelvises were carefully dissected to reveal the path and intersections of the nerves as they exit laterally from the sacral foramina. Our dissections revealed a variable network of connectivity, from the S1 dorsal sacral rami to the S4 dorsal sacral rami, that runs laterally to the long dorsal sacroiliac ligament and terminates in a confluence of sacrococcygeal connective tissue. The dorsal rami of the posterior sacral nerve roots form a neural network consistent with a true nervous plexus; we designated the dorsolateral sacral plexus. Connecting with the coccyx, the dorsolateral sacral plexus may provide a putative neurophysiologic conduit between the lumbar spine and pelvis (notably the pelvic floor). Future studies are warranted to determine if the dorsolateral sacral plexus plays a role in lumbopelvic pain or mechanical phenomena.

Mini-abstract: The sacral dorsal rami lateral branches form a variable and complex plexus, the dorsolateral sacral plexus, which terminates in a confluence of sacrococcygeal connective tissue.

Keywords: Biomechanical phenomena; Cadaver; Humans; Sacral plexus; Sacroiliac joint

\section{Introduction}

In previous studies we demonstrated that the sacroiliac joint (SIJ) is a well innervated structure and most likely a significant cause of low back pain as well as sciatica [1-3]. The SIJ is known to be innervated by the lateral branches of the dorsal sacral rami [46]. Accordingly, the path and origin of these rami have been investigated recently to improve the accuracy of interventional anesthesia and radiofrequency ablation of the SIJ nerve supply [6-8]. There is, however, no study that clearly defines the relationship of these nerves lateral to the joint proper. In Gray's 1918 definitive publication of comprehensive anatomy, there is a brief description and illustration of the posterior sacral nerves as they exit the sacrum (Figure 1a/1b). A publication which provided the sole anatomical reference to the dorsal sacral rami until Braus published a nearly identical description over four decades later $[9,10]$. Neither of the aforementioned publications accurately detail the neural connectivity lateral to the SIJ proper. Moreover, in the peer reviewed literature there is no reference to or description of the caudal-most connectivity and terminations of these nervous structures. This data is fundamental to ultimately determine the complete range of dorsal sacral rami signaling pathways and potentially related electrophysiologic phenomenon. The purpose of this study was to: 1) examine the contributions of the lateral branches of the dorsal sacral rami to the region lateral and inferior to the SIJ and 2) define their connectivity as well as termination(s). 

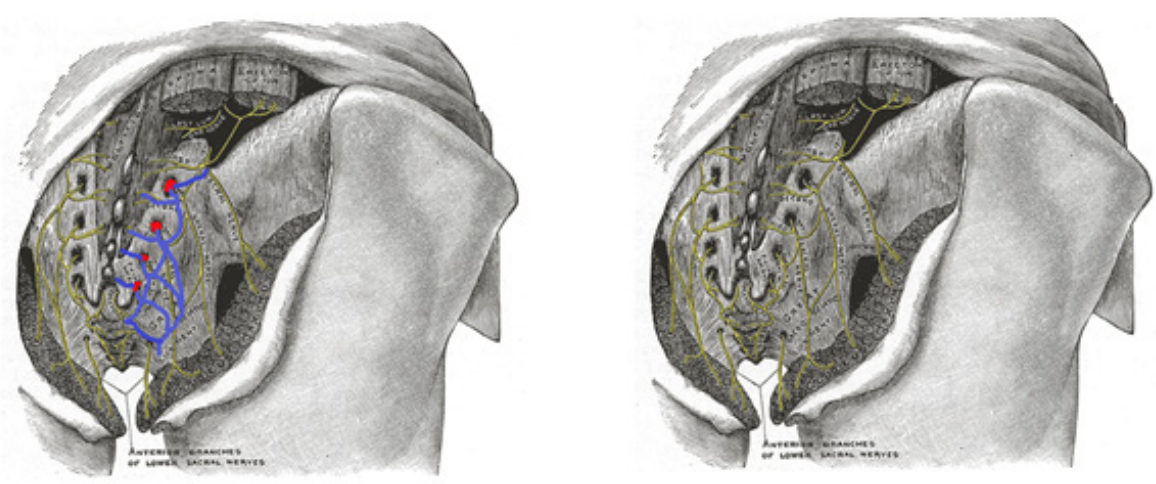

Figure 1a/1b: For comparison, by H.V. Carter (from Henry Gray's 1918 Anatomy of the Human Body). The right image is the original drawing from the text. Note the omission of the lateral-most connectivity of the plexus. The image on the left has been modified with the superimposed blue lines by the current authors, to indicate the plexus as observed in the authors' dissections.

\section{Materials and Methods}

Ten embalmed cadaveric hemipelvises were dissected for this study. None of the specimens had evidence of surgery or pathology in the area of dissection. The age of the specimens at the time of their death ranged from sixty-five to eighty-eight years old. First, the skin and fat were grossly dissected to reveal the gluteal musculature. The muscles were carefully dissected to expose all four sacral foramina. As much connective tissue as possible was removed in an attempt to visualize the sacral nerves without transection or displacement. The short and long sacroiliac and sacrotuberous ligaments were removed when appropriate to disclose the middle cluneal nerve point of entry. The lateral branches were meticulously traced to their termination at the posterolateral sacrococcygeal ligaments or sacrococcygeal joint (SCJ) capsular confluence. Because the structures under investigation were small and superimposed against a confluent background of stromal and periosteal tissue, the foramina and nerves were painted with a fine tipped brush to highlight their positions. All specimens were photographed, and the plexus connectivity/terminations were recorded.

\section{Result}

At the level of the dorsal sacral foramen, two primary branches of the dorsal rami are observed as they exit the foramen- a medical branch coursing toward midline and a laterally directed branch extending toward the sacroiliac ligament. The laterally directed branches form a plexus (i.e.a network of interlaced, interjoined or intermingled nerves), subsequently entitled the Dorsolateral Sacral Plexus (DLSP). At each sacral foramen the nerve segments can be seen providing individual or duplicate input to the DLSP. The lateral-most portion of the plexus lies in a shallow arc lateral to the posterior sacroiliac ligament-overlying the sacrotuberous ligament before diving medially to terminate within the confluence of connective tissue (lateral and superficial dorsal sacrococcygeal ligaments) immediately adjacent to or within the SCJ proper (Figure 2).

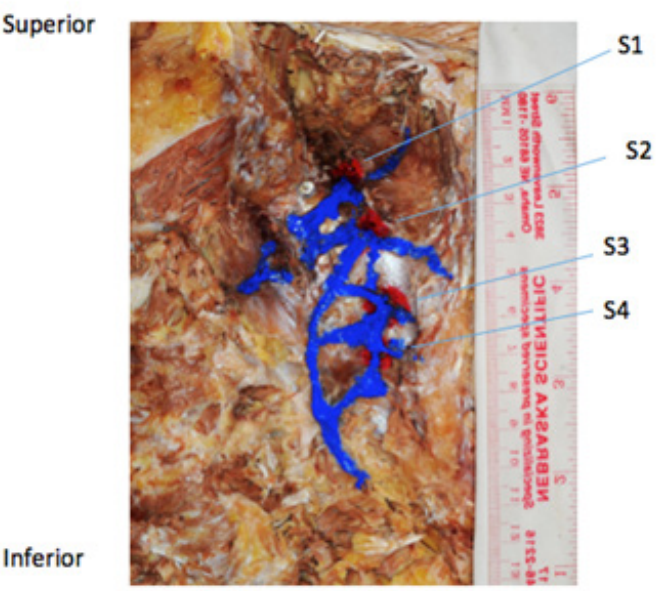

Figure 2: A left posterior hemipelvis dissection demonstrating the entire dorsolateral sacral plexus. The foramina have been painted red and the nerve roots blue for better visualization. 
Eight of the ten S1 dorsal rami branches we dissected combined with $\mathrm{S} 2$ branches prior to joining the plexus. Five of the ten S2 branches also contributed a branch to the plexus in conjunction with S3. It is important to note that in addition to the formation of the DLSP, S2 and S3 combine in a range of configurations to form the middle cluneal nerve $[4,11]$, which penetrates the long posterior sacroiliac ligament. Continuing caudally, seven of the ten branches from S3 join an S4 branch. The conjoint branch then joins the plexus. The contributions of S4 were shown to be a single branch into the plexus near its termination at the sacrococcygeal ligaments or SCJ capsule in eight of ten specimens.

\section{Discussion}

Previous publications did not accurately depict the neural connectivity of the sacral dorsal rami lateral to the SIJ proper (visualized in our dissections), nor did their texts delineate the confluence of the dorsal rami that form the middle cluneal nerve. This investigation established that the lateral branches of the sacral dorsal rami form a true plexus. A plexus the authors labeled the dorsolateral sacral plexus, given its position relative to the sacrum, and the fact that its complex branching and intersecting patterns are consonant with every recognized definition of a nervous plexus [12-16] (as detailed in Table 1 and illustrated in the accompanying figures). Traversing almost the entire length of the sacrum; the DLSP receives variable contributions from the lateral branches of the sacral dorsal rami in diverse arrays. The DLSP originates adjacent the S1-S2 foramen and terminates at the posterolateral sacrococcygeal ligament/SCJ capsular complex. Once the plexus terminates in the sacrococcygeal ligaments and joint capsule, the nerves become too filamentous and friable to study on a gross level. While the clinical ramifications of related pain presentations are beyond the scope of the current study [17], the DLSP and SCJ myofascial pelvic floor connections (as well as the immediate proximity of the SCJ to the ganglion impar) may provide substrate for future investigations [18-20] (Figure 3-5) (Table 1).

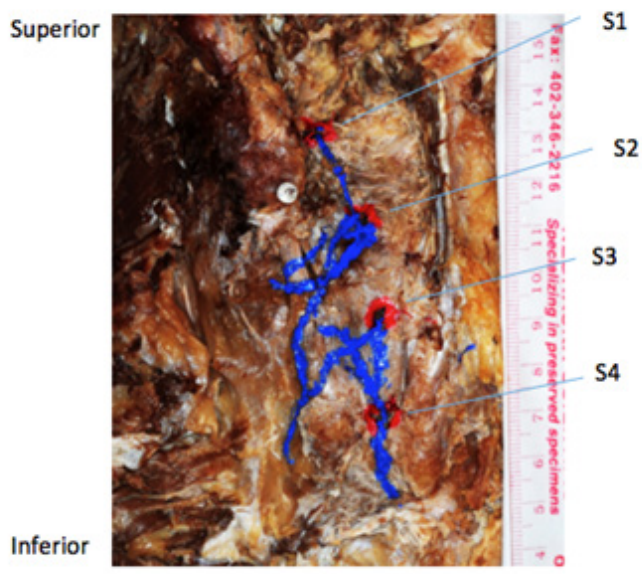

Figure 3: A left posterior hemipelvis dissection demonstrating the entire dorsolateral sacral plexus. The foramina have been painted red and the nerve roots blue for better visualization.

Table 1: Segmental contributions to the dorsolateral sacral plexus.]

\begin{tabular}{|c|c|c|c|c|c|}
\hline Specimen & Age & S1 & S2 & S3 & S4 \\
\hline 1 & 65 & S & $\mathrm{S}, \mathrm{C}(\mathrm{S} 3)$ & $\mathrm{C}(\mathrm{S} 2)$ & S \\
\hline 2 & 82 & $\mathrm{C}(\mathrm{S} 2)$ & $\mathrm{C}(\mathrm{S} 1)$ & S, C(S4) & $\mathrm{S}, \mathrm{C}(\mathrm{S} 3)$ \\
\hline 3 & 85 & $\mathrm{C}(\mathrm{S} 2)$ & $\mathrm{C}(\mathrm{S} 1, \mathrm{~S} 3)$ & $\mathrm{C}(\mathrm{S} 3, \mathrm{~S} 4)$ & $\mathrm{S}, \mathrm{C}(\mathrm{S} 3)$ \\
\hline 4 & 88 & $\mathrm{C}(\mathrm{S} 2)$ & $\mathrm{S}, \mathrm{C}(\mathrm{S} 1)$ & S, C(S4) & $\mathrm{S}, \mathrm{C}(\mathrm{S} 3)$ \\
\hline 5 & 80 & $\mathrm{C}(\mathrm{S} 2)$ & $\mathrm{S}, \mathrm{C}(\mathrm{S} 1)$ & $S$ & S \\
\hline 6 & 60 & $\mathrm{C}(\mathrm{S} 2)$ & $\mathrm{C}(\mathrm{S} 1, \mathrm{~S} 3)$ & $\mathrm{C}(\mathrm{S} 3, \mathrm{~S} 4)$ & $\mathrm{C}(\mathrm{S} 3)$ \\
\hline 7 & 75 & $\mathrm{C}(\mathrm{S} 2)$ & $\mathrm{S}, \mathrm{C}(\mathrm{S} 1)$ & S, C(S4) & $\mathrm{S}, \mathrm{C}(\mathrm{S} 3)$ \\
\hline 8 & 73 & S1 & $S$ & $\mathrm{C}(\mathrm{S} 4)$ & $\mathrm{S}, \mathrm{C}(\mathrm{S} 3)$ \\
\hline 9 & 68 & $\mathrm{C}(\mathrm{S} 2)$ & $\mathrm{C}(\mathrm{S} 1, \mathrm{~S} 3)$ & $\mathrm{C}(\mathrm{S} 2)$ & - \\
\hline 10 & 88 & $\mathrm{C}(\mathrm{S} 2)$ & $\mathrm{C}(\mathrm{S} 1, \mathrm{~S} 3)$ & $\mathrm{C}(\mathrm{S} 2, \mathrm{~S} 4)$ & S, C(S3) \\
\hline
\end{tabular}

$\mathrm{S}=$ direct contribution, $\mathrm{C}=$ combined contribution, parenthesis= segment(s) forming combined contributions 


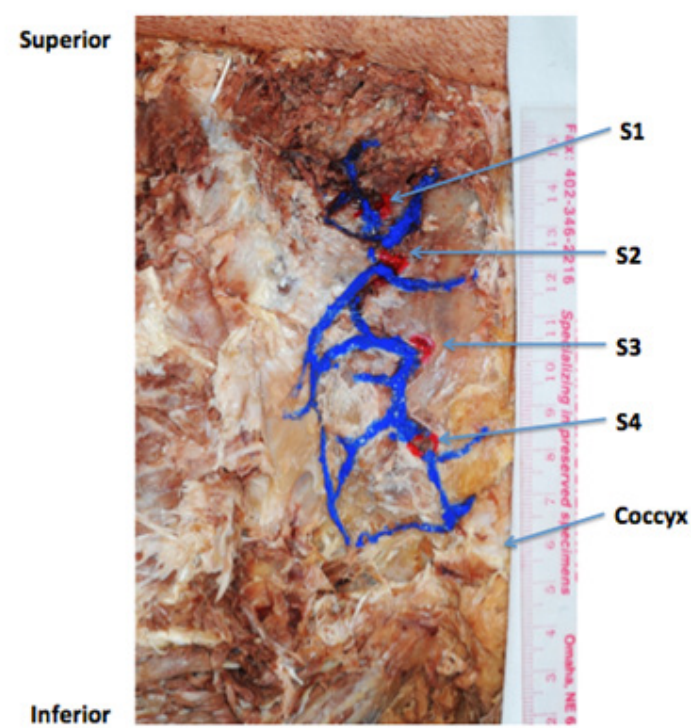

Figure 4: Left posterior hemipelvis dissection demonstrating the entire dorsolateral sacral plexus. The foramina have been painted red and the nerve roots blue for better visualization.

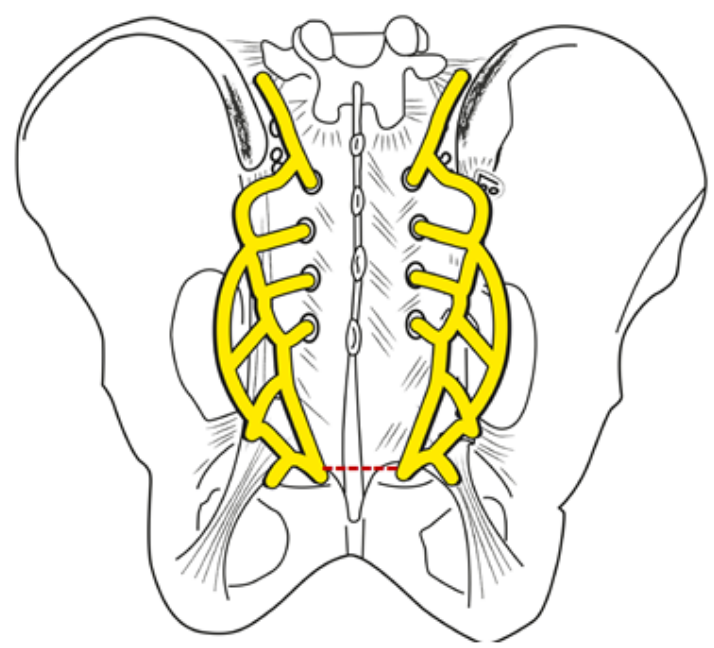

Figure 5: Line drawing depicting the sacral dorsal rami lateral branches and DLSP (yellow lines). Relative position of SCJ joint line (red dashed line).

\section{Author Contributions}

All authors contributed to the study conception and design. Protocol/project development, data analysis, and manuscript writing, and editing were performed by Joseph D Fortin data collection, data analysis, and manuscript writing and editing were performed by Ryan S. Dill. All authors read and approved the final manuscript.

\section{Acknowledgment}

Joel A Vilensky, PhD: Professor Emeritus of Anatomy \& Cell Biology, Indiana University School of Medicine for lending his expertise to the manuscript preparation. Prof. Dr. med. Rudolf Kissling: Senior Consultant Rheumatology, Balgrist University Hospital for providing the impetus for the current and past efforts concerning SIJ innervation. The Authors would also like to honor and recognize those who selflessly donated themselves to science to enable this research.

\section{Conflict of Interest}

The authors declare that they have no conflicts of interest.

\section{References}

1. Fortin JD, Dwyer A, Aprill C, Ponthieux B, Pier J (1994a) Sacroiliac joint pain referral patterns. II: Clinical evaluation. Spine 19(13): 1483-1489.

2. Fortin JD, Falco F, Washington W (1999a) Three pathways between the sacroiliac joint and neural structures exist. Am J Neurorad 20(8): 14291434. 
3. Goldthwaite GE, Osgood RB (1905) A consideration of the pelvic articulations from an anatomical, pathological, and clinical standpoint. Boston Med Surg J 152: 593-601.

4. Konno T, Aota Y, Saito T, Ning Qu, Shogo Hayashi, et al. (2017) Anatomical study of middle cluneal nerve entrapment. J Pain Research 10: 1431 1435.

5. Mixter WJ, Barr JS (1934) Rupture of the intervertebral disc with involvement of the spinal canal. New Eng J Med 211: 210-215.

6. Orduna Valls JM, Vallejo R, Lopez Pais P, et al. (2017) Anatomic and ultrasonographic evaluation of the knee sensory innervation: a cadaveric study to determine anatomic targets in the treatment of chronic knee pain. Reg Anesth Pain Med 42(1): 90-98.

7. Cox RC, Fortin JD (2014) The anatomy of the lateral branches of the sacral dorsal rami: implications for radiofrequency ablation. Pain Phys 17(5): 459-464.

8. Roberts SL, Burnham RS, Ravichandiran K, Agur AM, Loh EY (2014) Cadaveric study of sacroiliac joint innervation: implications for diagnostic blocks and radiofrequency ablation. Reg Anesth Pain Med 39(6): 456-464.

9. Gray H (1918) Anatomy of the Human Body. $20^{\text {th }}$ ed, revised and reedited by Warren H. Lewis, Lea \& Febiger.

10. Braus, H Anatomie Des Menschen: Dritter Band, Springerr, Verlag, Berlin, Gottingen, Heidelberg (1960).

11. Sembrano JN, Polly W (2009) How often is low back pain not coming from the back? Spine 34(1): E27-E32.
12. Dorland WA (2011) 'Plexus'. In: Dorland's illustrated medical dictionary, 32nd edn, Saunders, Philadelphia.

13. Law J \& Martin E (2020) 'Plexus'. In: Oxford's concise medical dictionary, $10^{\text {th }}$ edn, Oxford University Press.

14. Mosby CV (2016) 'Plexus'. In: O Toole M ed. Mosby’s medical dictionary, $10^{\text {th }}$ edn, Mosby, Missouri.

15. Stedman TL (2005) 'Plexus'. In: Stedman's medical dictionary, $28^{\text {th }}$ edn, Wolters Kluwer Health.

16. Venes D (2017) ‘Plexus'. In: Taber's cyclopedic medical dictionary, $23^{\text {rd }}$ edn, FA Davis Company, Philadelphia.

17. Hansen HC, McKenzie-Brown AM, Cohen SP, Swicegood JR, Colson JD, et al. (2007) Sacroiliac joint interventions: a systematic review. Pain Phys 10(1): 165-184

18. Fortin JD, Rudolf O, Kissling RO, O Connor BL, Vilensky JA (1999b) Sacroiliac joint innervation and pain. Am J Orthop 28(12): 687-690.

19. Fortin JD, Vilensky JA, Merkel GJ (2003) Can the Sacroiliac Joint Cause Sciatica? Pain Phys 6: 269-271.

20. Braus, H Anatomie Des Menschen: Dritter Band, Springerr, Verlag, Berlin, Gottingen, Heidelberg (1960). 